\title{
Determinants of Anemia among women in Uganda: further analysis of the Uganda demographic and health surveys
}

\author{
Olivia Nankinga ${ }^{1 *}$ (D) and Danstan Aguta $^{2}$
}

\begin{abstract}
Background: Anemia is a public health problem in many developing countries. It affects a sizable proportion of women of reproductive age. Anemia increases the risk of morbidity and mortality from infectious diseases, and can lead to poor fetal outcomes, and low productivity. This study examined the trends and determinants of anemia among women of reproductive age in Uganda.

Methods: This study analyzed data from the Uganda Demographic and Health Surveys conducted in 2006, 2011, and 2016. The study was based on 10,956 weighted cases of women age 15-49. Bivariate analysis and multiple logistic regression analysis examined the association between the outcome variable and the determinants. Potential determinants of anemia in women were selected based on literature.

Results: The results of the analysis show that anemia decreased in Uganda between 2006 and 2016, but with an increase between 2011 and 2016. The overall prevalence of anemia among women was 50, 23, and 32\% respectively in 2006, 2011, and 2016. Women who were pregnant at the time of the survey had higher odds of being anemic across the surveys (OR 2.00, 95\% Cl 1.49-2.67; OR 1.47, 95\% Cl 1.02-2.10; OR 1.33, 95\% Cl 1.07-1.65). Women in households with nonimproved sources of drinking water also had higher odds for anemia (OR 1.32, 95\% Cl 1.09-1.61) in 2016. Wealth index, region and age were also significantly associated with anemia in women.

Conclusion: In order to reduce anemia in women, there is need to target pregnant women during antenatal and postpartum visits, and ensure that nutrition education during such visits is supported. There is also need to ensure sustainable household access to safe water. This should be combined with interventions aimed at enhancing household wealth.
\end{abstract}

Keywords: Anemia prevalence, Women of reproductive age, Anemia determinants, Uganda

\section{Background}

Anemia is a major public health concern [1], affecting approximately 1.6 billion people globally [2]. About one in every three women of reproductive age 15-49 suffers from anemia globally [3, 4]. In Africa, anemia affects $35 \%$ of women of reproductive age [4]. It also contributes significantly to the global disability burden.

Anemia is caused by many factors, including iron deficiency, infections, genetics, and other nutritional deficiencies [3-7]. The effects of anemia in a population are

\footnotetext{
* Correspondence: onankinga@gmail.com

'Department of Population Studies, School of Statistics and Planning, College of Business and Management Sciences, Makerere University, Kampala,

Uganda

Full list of author information is available at the end of the article
}

both short and long term. In pregnant women, anemia is related to poor maternal health and fetal outcomes, which may include infections, illnesses, and possible death for both the mother and the baby $[4,8]$.

Reported risk factors for anemia in women include residence, socioeconomic status, maternal education, and pregnancy status $[5,9,10]$. Women of reproductive age have higher risk of anemia due to regular blood loss with menstruation, pregnancy, and childbirth [4]. If the dietary requirements during pregnancy are not met or no iron supplements are taken, the risk of anemia among this group increases. In a number of households in developing countries, iron-rich foods needed to

(C) The Author(s). 2019 Open Access This article is distributed under the terms of the Creative Commons Attribution 4.0 International License (http://creativecommons.org/licenses/by/4.0/), which permits unrestricted use, distribution, and 
replenish such blood loss in women are either missing or insufficient [11].

Many countries have sought support to combat this preventable public health concern. In 2014, a comprehensive plan on maternal, infant, and young child nutrition was approved by the World Health Assembly, with anemia being one of the global targets for reduction (by $50 \%$ ) by 2025 and subsequent alleviation [3, 12]. Furthermore, countries including India, Pakistan, Ethiopia, Yemen, Nigeria, Malawi, and Uganda have systematically established investigations to understand the problems in their local contexts in order to design targeted approaches to combat the condition [10,13-15].

In Uganda the Ministry of Health has put in place deliberate interventions to improve maternal and child health outcomes through the Reproductive, Maternal, Neonatal and Child Health Sharpened Plan [16]. In addition, with support from development partners, the government embarked on a number of multisectoral nutrition interventions that include: the production of biofortified and iron-rich crops, provision of iron, anthelmintic and Vitamin A supplementation, promotion of breastfeeding, complementary feeding, family planning, delayed cord clamping, intensified malaria prevention and treatment, promotion of hygiene through increased access to water, improved latrines, hand washing, and infectious disease prevention [17-19].

Despite multisectoral efforts to reduce the burden of anemia in Uganda, the 2016 Uganda Demographic and Health Survey (UDHS) reported that the prevalence of anemia was $53 \%$ in children age 6-59 months, up from $49 \%$ in 2011 , and was $32 \%$ in women of reproductive age, up from $23 \%$ in 2011 [20, 21].

Past studies in Uganda have examined anemia using survey data for specific districts or regions [10, 22-24], but few have used multiple DHS datasets or considered a country-wide anemia assessment. In contrast, our study addresses the above gap by analyzing the anemia situation at a national scale and considering nationally representative DHS data for three survey years (2006, 2011, and 2016). The analyses were conducted for women of reproductive age 15-49 years. The specific objective of this study was to identify factors associated with anemia in women in Uganda. We hypothesized that women in rural areas, poorer households, and with no education are more likely to be anemic. We further hypothesized that women who were not involved in decision making at household level would have a higher risk of anemia than those involved in decision making.

\section{Methods}

\section{Data source}

The study used datasets from the 2006, 2011, and 2016 Uganda Demographic and Health Survey (UDHS). The
UDHS is a nationally representative population-based household survey, conducted every 5 years. The UDHS uses a stratified two-stage cluster sampling procedure. In the first stage, clusters are selected from sampling frames using the most recent census. Households are selected from each cluster at the second stage. The UDHS captures information in such areas as births to women age 15-49, women's demographic and socioeconomic characteristics, household characteristics, maternal and child health and nutrition, access to health facilities and involvement in household decision making using questionnaires. It further includes testing of height and weight of women and children, and testing for anemia, malaria and Vitamin A deficiency $[20,21,25]$. In this study we only considered women whose blood sample had been drawn for testing, who had a test result for the anemia level, and who were usual members of the household in which they were surveyed. These criteria resulted in 10,956 weighted cases of women age 15-49 years for the three survey years. The total sample included 2672, 2539 and 5745 women in 2006, 2011 and 2016 survey years respectively.

\section{Measurement of outcome variable}

The dependent variable-woman's anemia status-was recoded from the anemia level variable in the DHS datasets. Anemia level was determined from the result of hemoglobin level from blood testing. During the survey, blood specimens were collected for eligible women who voluntarily consented to be tested. This was done by obtaining a blood sample from a drop of blood taken from a finger prick. Hemoglobin analysis was carried out on site using a portable Hemocue analyser. Results were provided both verbally and in writing and all severe cases were referred for follow-up care. Anemia is marked by low levels of hemoglobin in the blood. For the analysis, all nonpregnant women age 15-49 who had less than $11.0 \mathrm{~g}$ of hemoglobin per deciliter $(\mathrm{g} / \mathrm{dl})$ were coded as anemic. Among pregnant women, those with hemoglobin values less than $12.0 \mathrm{~g}$ per deciliter were considered anemic. Nonpregnant women with hemoglobin values below $4.0 \mathrm{~g}$ per deciliter and those above $18.0 \mathrm{~g}$ per deciliter $(\mathrm{g} / \mathrm{dl})$ were regarded as implausible. Also, hemoglobin values below $3.0 \mathrm{~g}$ per deciliter and those above $17.0 \mathrm{~g}$ per deciliter $(\mathrm{g} / \mathrm{dl})$ in pregnant women were regarded as implausible. All implausible cases were excluded from the analysis. For the analysis, woman's anemia status was recoded into a binary outcome variable. All women whose anemia level was severe, moderate, or mild, were recoded as yes, and nonanemic cases were recoded as no.

\section{Measurement of other explanatory variables}

For the analysis, covariates were selected based on literature $[4,26,27]$. Covariates were grouped into three 
categories: community, household and individual variables. Community-level variables included place of residence and region. The region variable for the 2011 and 2016 UDHS was recoded as in the 2006 UDHS, for comparability. It was categorized as Kampala, Central 1, Central 2, East Central, Eastern, Northern, West Nile, Western, and South Western.

Household-level variables included wealth index, sex of the household head, type of toilet facility, source of drinking water, and number of children in the household. Wealth index is a composite measure of a household's living standards. It is calculated using data on a household's ownership of assets, household construction materials, and water and sanitation facilities [28]. Wealth index was coded as 1 poorest, 2 poorer, 3 middle, 4 richer, and 5 richest. Sex of the household head was coded as 1 male and 2 female. Type of toilet facility was recoded as 1 improved toilet, 2 shared toilet, 3 nonimproved toilet, and 4 no facility. Source of drinking water was grouped into improved and nonimproved as in the DHS grouping.

Individual-level variables for women included age, educational attainment, involvement in decision-making, ever giving birth, access to health services and pregnancy status. Age was coded into seven 5-year groups: 15-19, 20-24, 25-29, 30-34, 35-39, 40-44, and 45-49, for better illustration of results [20]. Educational attainment was coded as 0 no education, 1 primary, 2 secondary, and 3 higher. Involvement in decision-making was generated from three variables: Women who were involved in decision-making individually or jointly with their partner regarding spending of their income, their own health care, and household purchases were recoded as 1 involved, otherwise 0 not involved. All missing cases were recoded as 9 .

Women who reported having given birth were recoded as 1 yes, otherwise 0 no. Access to health care was recoded as 1 yes, otherwise 0 no, depending on whether distance to facility was reported as a big problem in accessing health care or not. Pregnancy status was coded as 1 yes for women who reported that they were pregnant at the time of the survey, and 0 no for women who were not pregnant or not sure of their status.

\section{Statistical analyses}

Only women who had plausible results of the blood hemoglobin levels were included in the analyses. Data were weighted using the women's individual sample weight to adjust for nonresponse and disproportionate selection. The svy command was used to account for complex survey design. The independent variables were tested for multicollinearity using the pairwise correlation coefficient and only variables with a relationship below 0.5 cutoff were included in the analysis [29].
Bivariate analyses were conducted to examine association between the dependent variable (anemia) and the explanatory variables. Pearson's chi-squared ( $x 2)$ tests were used to examine the significant differences between anemia and the explanatory variables. Statistical significance using $p$-values was set at $p<0.05$. Multivariate logistic regressions were used to examine the relationship between anemia status and the determinant variables. The results are presented for four models: Model 1 for 2006; Model 2 for 2011; Model 3 for 2016; and Model 4 for pooled data for the 3 survey years. Adjusted odds ratios and $95 \%$ confidence intervals are presented. All analyses were conducted using Stata version 15, and results are reported for the UDHS survey years 2006, 2011, and 2016.

\section{Results}

\section{Descriptive and bivariate analyses}

Results of the analysis of data presented in Table 1 show that 64,31 , and $38 \%$ of pregnant women were anemic in 2006, 2011, and 2016 respectively, substantially higher than the prevalence of anemia among nonpregnant women, at 48,22 , and $31 \%$ in the respective survey years. By women's involvement in household decisionmaking, 52, 24, and 30\% of women who reported being involved in decision-making in 2006, 2011, and 2016 respectively were anemic, somewhat lower than the 53,30 , and $36 \%$ of women who were not involved in decisionmaking. Anemia was also associated with household toilet facility; across the survey years 59, 33 and $39 \%$ of women in households that reported no toilet facility were anemic. Region was significantly associated with anemia among women, though the prevalence varied across regions. Further, women in poorer households had higher prevalence of anemia than those in wealthier households across the survey years.

\section{Multivariate logistic regression analysis}

Table 2 shows that women who were pregnant at the time of the survey had higher odds of being anemic compared with those who were not pregnant, for all the survey years (OR 2.00, 95\% CI 1.49-2.67; OR 1.47, 95\% CI 1.02-2.10; OR 1.33, 95\% CI 1.07-1.65) and for the pooled results (OR 1.49, 95\% CI 1.28-1.73). Higher odds for anemia were observed among women with nonimproved sources of drinking water in 2016, and for the pooled results (OR 1.32, 95\% CI 1.08-1.61; OR 1.18, 95\% CI 1.03-1.36) compared with women in households with improved sources of water. Also, women age 35-39 had higher odds for anemia compared with women age 15-19 in 2011 (OR 1.99, 95\% CI 1.27-3.14). Rural women had higher odds (OR 1.61, 95\% CI 1.01-2.56) of anemia compared with urban women in 2006. 
Table 1 Proportion of women age 15-49 who were anemic over the survey years by background characteristics, UDHS 2006, 2011, 2016

\begin{tabular}{|c|c|c|c|c|c|c|c|c|}
\hline \multirow[t]{2}{*}{ Characteristic } & \multicolumn{2}{|c|}{2006 UDHS } & \multicolumn{2}{|c|}{2011 UDHS } & \multicolumn{2}{|c|}{2016 UDHS } & \multicolumn{2}{|c|}{ Pooled Data } \\
\hline & $\begin{array}{l}\text {-value/ } \\
\text { percent }\end{array}$ & $n$ & $\begin{array}{l}\text { p-value/ } \\
\text { percent }\end{array}$ & $n$ & $\begin{array}{l}\text { p-value/ } \\
\text { percent }\end{array}$ & $n$ & $\begin{array}{l}p \text {-value/ } \\
\text { percent }\end{array}$ & $n$ \\
\hline Place of residence & $(0.000)$ & & $(0.140)$ & & $(0.003)$ & & $(0.000)$ & \\
\hline Urban & 35.0 & 429 & 19.9 & 509 & 27.5 & 1485 & 27.2 & 2423 \\
\hline Rural & 52.5 & 2244 & 23.8 & 2030 & 32.9 & 4260 & 35.9 & 8534 \\
\hline Region & $(0.000)$ & & $(0.000)$ & & $(0.000)$ & & $(0.000)$ & \\
\hline Kampala & 33.2 & 204 & 19.6 & 243 & 25.3 & 294 & 25.6 & 741 \\
\hline Central1 & 59.7 & 284 & 23.6 & 261 & 27.8 & 757 & 33.9 & 1303 \\
\hline Central2 & 42.1 & 240 & 30.3 & 243 & 31.6 & 614 & 33.6 & 1097 \\
\hline East Central & 48.9 & 257 & 29.8 & 269 & 39.2 & 608 & 39.1 & 1134 \\
\hline Eastern & 50.4 & 369 & 28.4 & 378 & 27.3 & 916 & 32.7 & 1663 \\
\hline Northern & 63.8 & 405 & 21.0 & 290 & 41.2 & 754 & 43.4 & 1449 \\
\hline West Nile & 37.4 & 149 & 32.1 & 161 & 39.8 & 374 & 37.4 & 685 \\
\hline Western & 45.5 & 409 & 17.4 & 372 & 30.5 & 754 & 31.3 & 1535 \\
\hline South Western & 50.1 & 353 & 11.7 & 324 & 23.0 & 675 & 27.4 & 1352 \\
\hline Wealth index & $(0.000)$ & & $(0.029)$ & & $(0.000)$ & & $(0.000)$ & \\
\hline Poorest & 57.9 & 468 & 28.6 & 446 & 40.7 & 1037 & 42.0 & 1952 \\
\hline Poorer & 55.9 & 520 & 26.4 & 448 & 32.9 & 1029 & 37.4 & 1998 \\
\hline Middle & 50.4 & 500 & 19.4 & 469 & 30.8 & 1079 & 32.9 & 2048 \\
\hline Richer & 48.1 & 527 & 22.2 & 540 & 31.0 & 1168 & 32.9 & 2235 \\
\hline Richest & 39.6 & 657 & 20.2 & 636 & 25.0 & 1432 & 27.4 & 2725 \\
\hline Type of toilet facility & $(0.001)$ & & $(0.044)$ & & $(0.000)$ & & $(0.000)$ & \\
\hline Improved toilet & 44.8 & 244 & 21.7 & 422 & 29.7 & 1318 & 29.8 & 1985 \\
\hline Shared toilet & 42.2 & 431 & 22.9 & 501 & 26.8 & 1090 & 29.2 & 2022 \\
\hline Nonimproved toilet & 50.7 & 1701 & 22.0 & 1403 & 33.2 & 3018 & 35.5 & 6122 \\
\hline No facility & 58.8 & 291 & 33.0 & 212 & 39.3 & 319 & 44.6 & 822 \\
\hline Source of drinking water & $(0.071)$ & & $(0.948)$ & & $(0.023)$ & & $(0.001)$ & \\
\hline Improved & 48.1 & 1849 & 23.0 & 1865 & 30.6 & 4585 & 32.8 & 8298 \\
\hline Nonimproved & 53.2 & 823 & 23.2 & 675 & 35.3 & 1160 & 37.8 & 2659 \\
\hline Sex of the household head & $(0.587)$ & & $(0.621)$ & & $(0.199)$ & & $(0.977)$ & \\
\hline Male & 50.1 & 1842 & 23.4 & 1715 & 30.8 & 3677 & 34.0 & 7233 \\
\hline Female & 48.7 & 831 & 22.4 & 824 & 32.7 & 2069 & 34.0 & 3724 \\
\hline Age group & $(0.295)$ & & $(0.008)$ & & $(0.113)$ & & $(0.021)$ & \\
\hline $15-19$ & 44.8 & 578 & 19.2 & 603 & 32.4 & 1290 & 29.9 & 2471 \\
\hline $20-24$ & 50.7 & 518 & 24.5 & 443 & 33.7 & 1160 & 36.0 & 2122 \\
\hline $25-29$ & 50.6 & 458 & 22.1 & 474 & 27.2 & 944 & 31.6 & 1875 \\
\hline $30-34$ & 50.2 & 396 & 18.1 & 323 & 30.8 & 802 & 33.1 & 1564 \\
\hline $35-39$ & 54.4 & 308 & 30.8 & 319 & 30.6 & 645 & 36.4 & 1272 \\
\hline $40-44$ & 51.1 & 240 & 25.9 & 195 & 33.5 & 538 & 36.3 & 973 \\
\hline $45-49$ & 48.9 & 174 & 27.1 & 181 & 32.9 & 366 & 35.3 & 722 \\
\hline Woman's level of education & $(0.018)$ & & $(0.211)$ & & $(0.050)$ & & $(0.000)$ & \\
\hline No education & 56.0 & 532 & 27.5 & 308 & 37.2 & 567 & 42.2 & 1406 \\
\hline Primary & 49.2 & 1585 & 22.9 & 1537 & 31.6 & 3308 & 33.8 & 6431 \\
\hline Secondary & 45.7 & 461 & 22.5 & 563 & 30.1 & 1460 & 31.3 & 2485 \\
\hline
\end{tabular}


Table 1 Proportion of women age 15-49 who were anemic over the survey years by background characteristics, UDHS 2006, 2011, 2016 (Continued)

\begin{tabular}{|c|c|c|c|c|c|c|c|c|}
\hline \multirow[t]{2}{*}{ Characteristic } & \multicolumn{2}{|c|}{2006 UDHS } & \multicolumn{2}{|c|}{2011 UDHS } & \multicolumn{2}{|c|}{2016 UDHS } & \multicolumn{2}{|c|}{ Pooled Data } \\
\hline & $\begin{array}{l}\text { p-value/ } \\
\text { percent }\end{array}$ & $n$ & $\begin{array}{l}\text { p-value/ } \\
\text { percent }\end{array}$ & $n$ & $\begin{array}{l}\text { p-value/ } \\
\text { percent }\end{array}$ & $n$ & $\begin{array}{l}\mathrm{p} \text {-value/ } \\
\text { percent }\end{array}$ & $n$ \\
\hline Higher & 41.4 & 94 & 16.8 & 131 & 28.6 & 409 & 28.0 & 635 \\
\hline Woman is currently pregnant & \multicolumn{2}{|l|}{$(0.000)$} & \multicolumn{2}{|l|}{$(0.006)$} & \multicolumn{2}{|l|}{$(0.006)$} & \multicolumn{2}{|l|}{$(0.000)$} \\
\hline No & 47.6 & 2344 & 22.1 & 2257 & 30.9 & 5156 & 32.9 & 9756 \\
\hline Yes & 64.4 & 329 & 30.6 & 283 & 37.3 & 589 & 43.2 & 1201 \\
\hline Woman has ever given birth & \multicolumn{2}{|l|}{$(0.001)$} & \multicolumn{2}{|l|}{$(0.017)$} & \multicolumn{2}{|l|}{$(0.750)$} & \multicolumn{2}{|l|}{$(0.001)$} \\
\hline No & 43.2 & 608 & 19.3 & 658 & 31.1 & 1446 & 30.9 & 2712 \\
\hline Yes & 51.6 & 2064 & 24.4 & 1881 & 31.7 & 4299 & 35.0 & 8245 \\
\hline $\begin{array}{l}\text { Whether woman is involved in } \\
\text { decision-making }\end{array}$ & \multicolumn{2}{|l|}{$(0.008)$} & \multicolumn{2}{|l|}{$(0.019)$} & \multicolumn{2}{|l|}{$(0.085)$} & \multicolumn{2}{|l|}{$(0.000)$} \\
\hline No & 52.6 & 377 & 29.6 & 310 & 35.7 & 437 & 39.7 & 1124 \\
\hline Yes & 51.9 & 1369 & 23.9 & 1278 & 30.3 & 3107 & 34.0 & 5755 \\
\hline Missing & 45.2 & 926 & 19.9 & 951 & 32.4 & 2201 & 32.4 & 4078 \\
\hline $\begin{array}{l}\text { Distance to facility a big } \\
\text { problem to woman }\end{array}$ & \multicolumn{2}{|l|}{$(0.182)$} & \multicolumn{2}{|l|}{$(0.127)$} & \multicolumn{2}{|l|}{$(0.019)$} & \multicolumn{2}{|l|}{$(0.000)$} \\
\hline No & 48.0 & 1252 & 21.7 & 1466 & 30.3 & 3581 & 31.8 & 6299 \\
\hline Yes & 51.1 & 1418 & 25.0 & 1073 & 33.6 & 2164 & 36.9 & 4656 \\
\hline Total & \multicolumn{2}{|c|}{$49.7(N=2672)$} & \multicolumn{2}{|c|}{$23.1(\mathrm{~N}=2539)$} & \multicolumn{2}{|c|}{$31.5(\mathrm{~N}=5745)$} & \multicolumn{2}{|c|}{$34.0(\mathrm{~N}=10,957)$} \\
\hline
\end{tabular}

Compared with the poorest households, the odds of anemia in women in the wealthier household quintiles were lower in 2016 (OR 0.80, 95\% CI 0.64-0.99; OR 0.74, 95\% CI 0.58-0.95; OR 0.74, 95\% CI 0.57-0.97; OR $0.55,95 \%$ CI $0.40-0.76$ ) and for the pooled results (OR 0.76, 95\% CI 0.63-0.91; OR 0.75, 95\% CI 0.62-0.90; OR $0.59,95 \%$ CI $0.47-0.76)$. The same pattern was observed in 2006 and 2011, although it was not statistically significant. Women age 25-29 had lower odds for anemia compared with women age 15-19 in 2016 (OR 0.75, 95\% CI 0.57-0.99). Women in the South Western region had lower odds for anemia compared with women in Kampala in 2011 (OR 0.40, 95\% CI 0.19-0.84) and 2016 (OR 0.59, 95\% CI 0.38-0.92), and for the pooled results (OR 0.71, 95\% CI 0.51-1.00). The pooled results in Table 2 show lower odds for women anemia in the 2011 and 2016 surveys (OR 0.30, 95\% CI 0.26-0.36; OR 0.47, 95\% CI 0.41-0.54) compared with 2006.

\section{Discussion}

This paper examined the trends and determinants of anemia among women of reproductive age in Uganda. Despite the many frameworks and policies for addressing Uganda's nutrition issues $[16,30,31]$, the country still faces various nutrition challenges.

This study shows that, although the prevalence of anemia among women in Uganda has declined since the 2006 UDHS, it increased between 2011 and 2016 and still affects a sizable proportion of women of reproductive age.
The overall prevalence of anemia among women in this study was 50\% in 2006, 23\% in 2011, and 32\% in 2016. Common risk factors for anemia among women include pregnancy, source of drinking water, age, residence, household wealth, and region.

Results show that the prevalence of anemia in women of reproductive age in Uganda was 32\%, nearly the same as the global average of $33 \%$ in 2016 [4]. This rate remains high despite the interventions by the Ministry of Health, including the indoor residual spraying, distribution of free insecticide-treated mosquito nets, and iron and vitamin supplementation for pregnant women, among others [16]. Poor health is a hindrance towards achieving the ultimate goal of health for all the population. This implies that substantial effort is needed to reduce the prevalence of anemia among women, since it affects maternal and child health and other development outcomes.

Pregnancy increased the odds of anemia in women. In pregnancy there is blood volume expansion [32], which consequently increases iron and folic acid demand. More blood is produced to support the growth of the baby but this is only possible if the body is able to produce the required amount of red blood cells. These physiological changes increase the risk of anemia, especially if the woman's dietary needs are not met. Anemia in pregnant women leads to poor fetal outcomes such as low birth weight and stillbirths, and can also lead to death of the mother $[10,19]$. More effort is therefore needed to 
Table 2 Adjusted odds ratios (AORs) for anemia among women age 15-49 across the survey years, UDHS 2006, 2011, 2016

\begin{tabular}{|c|c|c|c|c|c|c|c|c|}
\hline \multirow[t]{2}{*}{ Characteristic } & \multicolumn{2}{|l|}{2006 UDHS } & \multicolumn{2}{|l|}{2011 UDHS } & \multicolumn{2}{|l|}{2016 UDHS } & \multicolumn{2}{|l|}{ Pooled Data } \\
\hline & Odds Ratio & {$[95 \% \mathrm{Cl}]$} & Odds Ratio & {$[95 \% \mathrm{Cl}]$} & Odds Ratio & {$[95 \% \mathrm{Cl}]$} & Odds Ratio & {$[95 \% \mathrm{Cl}]$} \\
\hline \multicolumn{9}{|c|}{ Place of residence (rc: Urban) } \\
\hline Rural & $1.61^{*}$ & $1.01-2.56$ & 1.13 & $0.71-1.80$ & 0.94 & $0.77-1.15$ & 1.10 & $0.92-1.32$ \\
\hline \multicolumn{9}{|l|}{ Region (rc: Kampala) } \\
\hline Central1 & 1.60 & $0.78-3.29$ & 0.95 & $0.49-1.85$ & 0.92 & $0.63-1.32$ & 1.14 & $0.85-1.54$ \\
\hline Central2 & 0.76 & $0.38-1.52$ & 1.40 & $0.76-2.55$ & 1.00 & $0.67-1.48$ & 1.07 & $0.79-1.45$ \\
\hline East Central & 0.98 & $0.49-1.95$ & 1.35 & $0.74-2.46$ & 1.40 & $0.97-2.03$ & 1.33 & $0.98-1.80$ \\
\hline Eastern & 0.93 & $0.47-1.84$ & 1.10 & $0.55-2.18$ & 0.78 & $0.54-1.13$ & 0.91 & $0.67-1.24$ \\
\hline Northern & 1.65 & $0.81-3.36$ & 0.66 & $0.34-1.29$ & 1.35 & $0.92-1.98$ & 1.30 & $0.95-1.78$ \\
\hline West Nile & 0.58 & $0.30-1.13$ & 1.32 & $0.69-2.54$ & 1.31 & $0.83-2.05$ & 1.15 & $0.81-1.61$ \\
\hline Western & 0.79 & $0.39-1.60$ & 0.67 & $0.32-1.40$ & 0.92 & $0.61-1.37$ & 0.87 & $0.63-1.21$ \\
\hline South Western & 1.02 & $0.49-2.12$ & $0.40^{*}$ & $0.19-0.84$ & $0.59^{*}$ & $0.38-0.92$ & $0.71^{*}$ & $0.51-1.00$ \\
\hline \multicolumn{9}{|c|}{ Wealth index (rc: Poorest) } \\
\hline Poorer & 1.06 & $0.78-1.45$ & 0.93 & $0.64-1.35$ & $0.80^{*}$ & $0.64-0.99$ & 0.86 & $0.74-1.01$ \\
\hline Middle & 0.92 & $0.64-1.31$ & 0.74 & $0.48-1.15$ & $0.74^{*}$ & $0.58-0.95$ & $0.76^{* *}$ & $0.63-0.91$ \\
\hline Richer & 0.84 & $0.60-1.19$ & 0.85 & $0.56-1.29$ & $0.74^{*}$ & $0.57-0.97$ & $0.75^{* *}$ & $0.62-0.90$ \\
\hline Richest & 0.71 & $0.47-1.08$ & 0.77 & $0.39-1.53$ & $0.55^{* * *}$ & $0.40-0.76$ & $0.59^{* * *}$ & $0.47-0.76$ \\
\hline \multicolumn{9}{|c|}{ Type of toilet facility (rc: Improved) } \\
\hline Shared toilet & 0.89 & $0.62-1.28$ & 1.11 & $0.69-1.78$ & 0.89 & $0.69-1.14$ & 0.93 & $0.77-1.12$ \\
\hline Nonimproved toilet & 1.01 & $0.70-1.46$ & 1.00 & $0.68-1.49$ & 1.00 & $0.81-1.24$ & 0.98 & $0.83-1.16$ \\
\hline No facility & 1.03 & $0.64-1.68$ & 1.45 & $0.82-2.57$ & 0.90 & $0.65-1.25$ & 1.01 & $0.80-1.29$ \\
\hline \multicolumn{9}{|c|}{ Source of drinking water (rc: Improved) } \\
\hline Nonimproved & 1.09 & $0.85-1.40$ & 1.16 & $0.86-1.56$ & $1.32^{* *}$ & $1.08-1.61$ & $1.18^{*}$ & $1.03-1.36$ \\
\hline \multicolumn{9}{|c|}{ Sex of the household head (rc: Male) } \\
\hline Female & 1.01 & $0.80-1.28$ & 0.96 & $0.74-1.25$ & 1.05 & $0.90-1.22$ & 1.03 & $0.92-1.15$ \\
\hline \multicolumn{9}{|c|}{ Age of woman (rc: 15-19) } \\
\hline $20-24$ & 1.01 & $0.70-1.47$ & 1.32 & $0.85-2.05$ & 1.01 & $0.80-1.28$ & 1.06 & $0.88-1.26$ \\
\hline $25-29$ & 0.99 & $0.66-1.46$ & 1.16 & $0.75-1.80$ & $0.75^{*}$ & $0.57-0.99$ & 0.88 & $0.72-1.07$ \\
\hline $30-34$ & 0.95 & $0.65-1.39$ & 0.93 & $0.57-1.52$ & 0.88 & $0.64-1.20$ & 0.91 & $0.73-1.12$ \\
\hline $35-39$ & 1.19 & $0.77-1.84$ & $1.99 * *$ & $1.27-3.14$ & 0.86 & $0.64-1.17$ & 1.11 & $0.89-1.37$ \\
\hline $40-44$ & 1.05 & $0.66-1.66$ & 1.48 & $0.87-2.52$ & 0.98 & $0.72-1.34$ & 1.07 & $0.85-1.34$ \\
\hline $45-49$ & 0.92 & $0.58-1.46$ & 1.68 & $0.96-2.95$ & 1.01 & $0.73-1.40$ & 1.07 & $0.84-1.36$ \\
\hline \multicolumn{9}{|c|}{ Woman's level of education (rc: None) } \\
\hline Primary & 0.89 & $0.71-1.12$ & 0.89 & $0.64-1.25$ & 0.85 & $0.69-1.04$ & 0.88 & $0.76-1.01$ \\
\hline Secondary & 1.13 & $0.81-1.58$ & 1.07 & $0.64-1.78$ & 0.96 & $0.74-1.25$ & 1.02 & $0.84-1.23$ \\
\hline Higher & 0.94 & $0.56-1.57$ & 0.81 & $0.40-1.62$ & 1.07 & $0.73-1.59$ & 1.01 & $0.76-1.35$ \\
\hline \multicolumn{9}{|c|}{ Woman currently pregnant (rc: No) } \\
\hline Yes & $2.00^{* * *}$ & $1.49-2.67$ & $1.47^{*}$ & $1.02-2.10$ & $1.33^{*}$ & $1.07-1.65$ & $1.49^{* * *}$ & $1.28-1.73$ \\
\hline \multicolumn{9}{|c|}{ Woman has ever given birth (rc: No) } \\
\hline Yes & 1.34 & $0.96-1.88$ & 0.90 & $0.59-1.35$ & 1.20 & $0.93-1.54$ & 1.17 & $0.98-1.40$ \\
\hline \multicolumn{9}{|c|}{ Woman involved in decision-making (rc: No) } \\
\hline Yes & 1.03 & $0.79-1.34$ & 0.76 & $0.51-1.15$ & 0.84 & $0.66-1.08$ & 0.86 & $0.73-1.02$ \\
\hline Missing & 1.04 & $0.76-1.44$ & 0.72 & $0.46-1.14$ & 1.00 & $0.75-1.32$ & 0.93 & $0.77-1.13$ \\
\hline
\end{tabular}

Distance to facility a problem (rc: No) 
Table 2 Adjusted odds ratios (AORs) for anemia among women age 15-49 across the survey years, UDHS 2006, 2011, 2016 (Continued)

\begin{tabular}{|c|c|c|c|c|c|c|c|c|}
\hline \multirow[t]{2}{*}{ Characteristic } & \multicolumn{2}{|l|}{2006 UDHS } & \multicolumn{2}{|l|}{2011 UDHS } & \multicolumn{2}{|l|}{2016 UDHS } & \multicolumn{2}{|l|}{ Pooled Data } \\
\hline & Odds Ratio & {$[95 \% \mathrm{Cl}]$} & Odds Ratio & {$[95 \% \mathrm{Cl}]$} & Odds Ratio & {$[95 \% \mathrm{Cl}]$} & Odds Ratio & {$[95 \% \mathrm{Cl}]$} \\
\hline Yes & 0.92 & $0.76-1.12$ & 1.12 & $0.88-1.43$ & 1.01 & $0.88-1.16$ & 1.02 & $0.92-1.13$ \\
\hline \multicolumn{9}{|l|}{ Survey year (rc: 2006) } \\
\hline 2011 & & & & & & & $0.30^{* * *}$ & $0.26-0.36$ \\
\hline 2016 & & & & & & & $0.47^{* * *}$ & $0.41-0.54$ \\
\hline Total observations & 2645 & & 2580 & & 5799 & & 11,024 & \\
\hline
\end{tabular}

Level of significance ${ }^{* * *} p<0.001,{ }^{* *} p<0.01,{ }^{*} p<0.05$

$\mathrm{Cl}$ : Confidence interval

rc: Reference category

emphasize proper nutrition for women during pregnancy and breastfeeding. Intermittent preventive treatment doses of sulphadoxine-pyrimethamine should also be given to pregnant women, including those in rural areas, to prevent malaria, since this is a predisposing factor for anemia [33, 34].

Our hypothesis related to residence and anemia was partially supported. Rural women were more likely to be anemic than urban women. Higher prevalence of anemia in rural areas may be attributed to problems of access to services including health services and household poverty. There is a considerably higher proportion of rural women who belong to poor households, that may have challenges with access to proper nutrition. This is consistent with findings elsewhere that showed that rural residence is related to poor health outcomes $[5,35]$ and lack of access to services including education and nutrition [36]. Though rural households primarily depend on agriculture, and therefore may have access to foods and vegetables, they are more likely to suffer from non-iron deficiency anemia. This may be caused by infections, chronic diseases or zinc deficiency.

We further hypothesized that women in poor households are more likely to be anemic. This hypothesis is partially supported by the results of this study. Similar to findings elsewhere, women in the poorest households had more anemia cases compared with women in wealthier households [37, 38]. This could be explained by the inability of women in poorer households to afford a good diet [39], pay for health care [40], and practice good sanitation compared with women in wealthier households. Poor households tend to consume foods that are nutrient-poor, and are likely to be foodinsecure. This implies that members in such poor households are at increased risk of anemia. Poor women are further likely to have challenges with regards to autonomy in household decision making. Women disproportionately bear the burden of provision of basic needs for their household members [41]. This implies that household poverty is likely to impact access and use of services by these women. There is need to ensure that all women have access to health services and information on proper feeding [42], especially in rural areas. In addition, there is need to strengthen poverty alleviation programs and women's employment opportunities in order to improve their economic status. There is also need to boost agricultural innovations and investments since a sizable proportion of households depend on agricultural livelihoods [43]. This has the potential not only to increase incomes of women, but also increase food and nutrition security among households. As women gain access to income, they spend more on health, nutrition and education within the household.

Though Humphrey et al. in 2009 [44], in a study in rural Zimbabwe, reported that water, sanitation, and hygiene interventions are unlikely to reduce stunting or anemia in children, our study found that source of drinking water was significantly associated with anemia in women. Results showed more anemia cases among women who used unsafe water compared with those with safe sources. This points to the risk of waterborne diseases such as diarrhea, dysentery, and typhoid, which may increase the risk of anemia in households that draw water from nonimproved sources. Waterborne diseases may be caused due to exposure to fecal matter in such open sources of water. There is therefore need for the government to ensure that all households have access to safe water sources, so that such diseases are prevented. Prevention of these diseases is important to the particular households and also reduces the circulation of diseases within the community.

Women's age was associated with anemia prevalence. Higher levels of anemia were observed among older women. This may be explained by blood loss during childbirth, which increases the risk of anemia [6]. On the other hand, anemia among teenagers may be explained by the increased needs for iron during adolescence and blood loss during menstruation cycles [45, 46]. Family planning interventions should be strengthened to prevent early pregnancy through reaching out to adolescents in school and also those out of school. Further, all women of reproductive age should take iron and 
folic acid supplementation to prevent anemia [47]. Multisectoral programmes aimed at addressing nutritionrelated problems among all socioeconomic categories of women would be important in reducing anemia in women.

The research findings should be considered in light of some limitations with the study. The study was based on data from a cross-sectional survey, and therefore it was not possible to assess the cause-effect relationship between variables. It is self-reported information provided by survey respondents, which may be subject to recall bias. The study did not include dietary data because this information was only collected for children under age 24 months, yet, the study considered women of the reproductive age 15-49 years. It was therefore not possible to assess associations between diet and the anemia status of women in our sample. Nevertheless, the study offers insights into the high levels of anemia among women of reproductive age in Uganda, that could be a basis for interventions.

\section{Conclusion}

The results suggest that empowerment of women with economic resources, power to make decisions on spending household incomes, and access to health care should be prioritized in order to reduce anemia in women. More focus should be given to nutrition during antenatal and postpartum visits to health facilities. Health facilities should encourage supplementary feeding for boosting immunity for pregnant mothers since pregnancy increases the risk of anemia. This can be supported by setting up nutrition units in health facilities. Teenagers need to be continuously sensitized to the risks of teenage pregnancies and supported to stay in school. In cases of pregnancies, adolescent-friendly services should be available to support teenagers during pregnancy and motherhood. Family planning services should be extended to all women and teenagers who need them. Effective implementation of interventions to combat anemia in women will significantly reduce morbidity and mortality and other adverse consequences of anemia.

\section{Abbreviations \\ CI: Confidence Interval; UBOS: Uganda Bureau of Statistics; UDHS: Uganda Demographic and Health Surveys}

\footnotetext{
Acknowledgements

The authors are grateful for the financial and technical support provided by the United States Agency for International Development (USAID) through The DHS Program (\#AID-OAA-C-13-00095) of ICF International. We appreciate the valuable contributions, comments and reviews by the DHS program facilitators, Julia Fleuret, Dr. Ann Mwangi and Dr. Jupiter Simbeye, during the conceptualization of the study, analysis, and report writing, and Dr. Ann Mwangi and Dr. Rukundo Benedict for review of the draft paper. We highly appreciate Bryant Robey for the initial editorial input, and Catherine Kabahuma of Ministry of Health for her input in the initial stages of the manuscript. We are grateful to the reviewers for the useful comments and suggestions, which helped us to improve the manuscript.
}

\section{Authors' contributions}

ON and DA conceived and designed the study. ON wrote the background section reviewed literature. ON and DA analysed the data, interpreted the results and participated in the drafting of the manuscript. ON and DA read, reviewed and approved the final manuscript.

\section{Funding}

The research was supported by the United States Agency for International Development (USAID) through The DHS Program (\#AID-OAA-C-13-00095) of ICF International. USAID supported Makerere University DHS fellows, the Uganda Bureau of Statistics (UBOS) and Ministry of Health, Uganda (MOH) to conduct further analysis of the results of the UDHS survey. The DHS Program identified themes from which the authors designed the study, analyzed and interpreted data and wrote a working paper and manuscripts. The USAID facilitated a writing workshop and supported the final review of the working paper. The views expressed are those of the authors and not necessarily those of USAID.

\section{Availability of data and materials}

The datasets analyzed during the current study are available in the public domain at (URL: https://www.dhsprogram.com/data/available-datasets.cfm) upon registration at the DHS program website. We used the UGIR files (Women's recode - Women age 15-49 with complete interviews).

\section{Ethics approval and consent to participate}

No formal ethical clearance was required since the study was based on secondary data analysis. The authors got permission to use the data by written consent from the DHS program website, https://www.dhsprogram. com/data/available-datasets.cfm. The ORC MACRO Institutional Review Board (IRB) reviewed and approved the 2006 UDHS. The ICF Macro IRB reviewed and approved the MEASURE Phase III Demographic and Health Surveys Program (also known as DHS-6), and the 2011 UDHS is categorized under that approval; UBOS carried out the 2011 UDHS within its mandate provided in the UBOS Act of 1998. The ICF IRB reviewed and approved the 2016 UDHS. The ORC MACRO, ICF Macro, and ICF IRBs complied with the United States Department of Health and Human Services regulations for the protection of human research subjects (45 CFR 46). Further details regarding the conduct of the study may be found in the 2016 UDHS report [20].

\section{Consent for publication}

All authors have approved the submission of the manuscript.

\section{Competing interests}

The authors declare that they have no competing interests.

\section{Author details}

'Department of Population Studies, School of Statistics and Planning, College of Business and Management Sciences, Makerere University, Kampala, Uganda. ${ }^{2}$ Uganda Bureau of Statistics, Statistics House, Kampala, Uganda.

Received: 23 July 2019 Accepted: 19 December 2019

Published online: 30 December 2019

\section{References}

1. World Health Organization: The global prevalence of anaemia in 2011. 2015.

2. De Benoist B, Cogswell M, Egli I, McLean E. Worldwide prevalence of anaemia 1993-2005; WHO global database of anaemia; 2008.

3. World Health Organization: Comprehensive Implementation Plan on Maternal, Infant and Young Child Nutrition. In. Geneva, Switzerland: WHO; 2014

4. World Health Organization: Nutritional Anaemias: Tools for Effective Prevention and Control. In.: Geneva: World Health Organization; 2017.

5. Bharati P, Som S, Chakrabarty S, Bharati S, Pal M. Prevalence of Anemia and its determinants among nonpregnant and pregnant women in India. Asia Pacific Journal of Public Health. 2008;20(4):347-59.

6. Kassebaum NJ, Jasrasaria R, Naghavi M, Wulf SK, Johns N, Lozano R, Regan M, Weatherall D, Chou DP, Eisele TP, et al. A systematic analysis of global anemia burden from 1990 to 2010. Blood. 2014;123(5):615-24.

7. Stevens GA, Finucane MM, De-Regil LM, Paciorek CJ, Flaxman SR, Branca F, Peña-Rosas JP, Bhutta ZA, Ezzati M. Global, regional, and national trends in haemoglobin concentration and prevalence of total and severe anaemia in 
children and pregnant and non-pregnant women for 1995-2011: a systematic analysis of population-representative data. Lancet Glob Health. 2013;1 (1):e16-25.

8. Ndibazza J, Muhangi L, Akishule D, Kiggundu M, Ameke C, Oweka J, Kizindo R, Duong T, Kleinschmidt I, Muwanga $M$, et al. Effects of deworming during pregnancy on maternal and perinatal outcomes in Entebbe, Uganda: a randomized controlled trial. Clin Infect Dis. 2010;50(4):531-40.

9. Gebremedhin S, Enquselassie F, Umeta M. Prevalence and correlates of maternal anemia in rural Sidama, southern Ethiopia. Afr J Reprod Health 2014;18(1):44-53.

10. Kikafunda JK, Lukwago FB, Turyashemererwa F. Anaemia and associated factors among under-fives and their mothers in Bushenyi district. Western Uganda Public Health Nutrition. 2009;12(12):2302-8.

11. Torheim LE, Ferguson EL, Penrose K, Arimond M. Women in resource-poor settings are at risk of inadequate intakes of multiple micronutrients. J Nutr. 2010;140(11):2051S-8S

12. World Health Organization: Global Nutrition Targets 2025: Stunting policy brief. In. Geneva, Switzerland: WHO; 2014.

13. Al-alimi AA, Bashanfer S, Morish MA. Prevalence of Iron Deficiency Anemia among University Students in Hodeida Province, Yemen. Anemia. 2018; 2018:7.

14. Bekele A, Tilahun M, Mekuria A. Prevalence of Anemia and its associated factors among pregnant women attending antenatal Care in Health Institutions of Arba Minch town, Gamo Gofa zone. Ethiopia: A CrossSectional Study Anemia. 2016;2016:9.

15. Habib MA, Black K, Soofi SB, Hussain I, Bhatti Z, Bhutta ZA, Raynes-Greenow C. Prevalence and predictors of Iron deficiency Anemia in children under five years of age in Pakistan, a secondary analysis of National Nutrition Survey Data 2011-2012. PLoS One. 2016;11(5):e0155051.

16. Ministry of Health: Reproductive Maternal, Newborn and Child Health Sharpened Plan for Uganda. Committing to Child Survival. A promise Renewed. In. Kampala, Uganda: Government of Uganda, Ministry of Health; 2013.

17. Government of Uganda: National Nutritional Planning Guidelines for Uganda. In. Kampala, Uganda; 2015.

18. Ministry of Health: Integrated Management of Malnutrition Guidelines. In. Kampala, Uganda: Government of Uganda, Ministry of Health; 2010.

19. USAID. USAID Uganda country development cooperation strategy 20162021. Uganda: Kampala; 2016.

20. Uganda Bureau of Statistics - UBOS, ICF: Uganda Demographic and Health Survey 2016. In. Kampala, Uganda: UBOS and ICF; 2018.

21. Uganda Bureau of Statistics, ICF International Inc: Uganda Demographic and Health Survey 2011. In. Calverton, Maryland, USA; 2012.

22. Kiggundu VL, O'Meara WP, Musoke R, Nalugoda FK, Kigozi G, Baghendaghe E, Lutalo T, Achienge MK, Reynolds SJ, Makumbi F, et al. High prevalence of malaria Parasitemia and Anemia among hospitalized children in Rakai. Uganda Plos ONE. 2013;8(12):e82455.

23. Kuziga F, Adoke Y, Wanyenze RK. Prevalence and factors associated with Anaemia among children aged 6 to 59 months in Namutumba district. Uganda: A Cross-sectional Study BMC Pediatrics. 2017;17(1):25.

24. Legason ID, Atiku A, Ssenyonga R, Olupot-Olupot P, Barugahare JB. Prevalence of Anaemia and associated risk factors among children in NorthWestern Uganda: a cross sectional study. BMC Hematology. 2017;17(1):10.

25. Uganda Bureau of Statistics - UBOS, Macro International: Uganda Demographic and Health Survey 2006. In. Calverton, Maryland, USA: UBOS and Macro International; 2007.

26. Bronfenbrenner U, Morris PA. The bioecological model of human development. In: Handbook of Child Psychology; 2006.

27. Pasricha S-R, Drakesmith H, Black J, Hipgrave D, Biggs B-A. Control of iron deficiency anemia in low- and middle-income countries. Blood. 2013; 121(14):2607-17.

28. Rutstein SO, Johnson K. The DHS wealth index. DHS comparative reports no. 6. ORC Macro: Calverton, Maryland; 2004

29. Vatcheva KP, Lee M, McCormick JB, Rahbar MH. Multicollinearity in Regression Analyses Conducted in Epidemiologic Studies. Epidemiology (Sunnyvale, Calif). 2016;6(2):227.

30. Government of Uganda: Uganda National Nutrition Plan (2011-2016) UNAP Scaling Up Multi-Sectoral Efforts to Establish a Strong Nutrition Foundation for Uganda's Development In Kampala; 2011.

31. Republic of Uganda: Second National Development Plan (NDPII) 2015/162019/20 2015
32. Ciliberto CF, Marx GF. Physiological changes associated with pregnancy. Update Anaesthesia. 1998;9:1-3.

33. Briand V, Cottrell G, Massougbodji A, Cot M. Intermittent preventive treatment for the prevention of malaria during pregnancy in high transmission areas. Malar J. 2007;6(1):160.

34. Falade CO, Yusuf BO, Fadero FF, Mokuolu OA, Hamer DH, Salako LA. Intermittent preventive treatment with Sulphadoxine-pyrimethamine is effective in preventing maternal and placental malaria in Ibadan, SouthWestern Nigeria. Malar J. 2007;6(1):88.

35. Adamu AL, Crampin A, Kayuni N, Amberbir A, Koole O, Phiri A, Nyirenda M, Fine P. Prevalence and risk factors for anemia severity and type in Malawian men and women: urban and rural differences. Popul Health Metrics. 2017; 15(1):12.

36. Sender J, Cramer C, Oya C. Identifying the most deprived in rural Ethiopia and Uganda: a simple measure of socio-economic deprivation. Journal of Eastern African Studies. 2018;12(3):594-612.

37. Ali S, Haidar J. Food security status and vulnerability to anemia among women of reproductive age in pastoralist communities of Somali regional state, Ethiopia: a comparative, community-based, cross-sectional study. Ethiop J Health Dev. 2019;33(1):28-37.

38. Dey S, Goswami S, Goswami M. Prevalence of Anaemia in women of reproductive age in Meghalaya: a logistic regression analysis. Turkish Journal of Medical Sciences. 2010;40(5):783-9.

39. Oldewage-Theron WH, Dicks EG, Napier CE. Poverty, household food insecurity and nutrition: coping strategies in an informal settlement in the Vaal triangle. South Africa Public Health. 2006;120(9):795-804.

40. Peters DH, Garg A, Bloom G, Walker DG, Brieger WR, Hafizur Rahman M. Poverty and access to health Care in Developing Countries. Ann N Y Acad Sci. 2008;1136(1):161-71.

41. Rakowski C: Engendering wealth and well-being: empowerment for global change: Routledge; 2018

42. Price S. Understanding the importance to health of a balanced diet. Nurs Times. 2005:101(1):30-1.

43. Uganda Bureau of Statistics - UBOS: The National Population and Housing Census 2014 - Main Report. In. Kampala, Uganda: UBOS; 2016.

44. Humphrey JH, Mbuya MNN, Ntozini R, Moulton LH, Stoltzfus RJ, Tavengwa NV, Mutasa K, Majo F, Mutasa B, Mangwadu G, et al. Independent and combined effects of improved water, sanitation, and hygiene, and improved complementary feeding, on child stunting and Anaemia in rural Zimbabwe: a cluster-randomised trial. Lancet Glob Health. 2019;7(1):e132-47.

45. Mesías M, Seiquer I, Navarro MP. Iron nutrition in adolescence. Crit Rev Food Sci Nutr. 2013;53(11):1226-37.

46. Story $\mathrm{M}$, Hermanson J. Nutrient needs during adolescence and pregnancy. Nutrition and the pregnant adolescent: a practical reference guide Minneapolis: Center for Leadership, Education, and Training in Maternal and Child Nutrition, University of Minnesota. 2000:37-46.

47. World Health Organization: Guideline: Intermittent Iron and Folic Acid Supplementation in Menstruating Women. In. Geneva: World Health Organization; 2011.

\section{Publisher's Note}

Springer Nature remains neutral with regard to jurisdictional claims in published maps and institutional affiliations.

Ready to submit your research? Choose BMC and benefit from:

- fast, convenient online submission

- thorough peer review by experienced researchers in your field

- rapid publication on acceptance

- support for research data, including large and complex data types

- gold Open Access which fosters wider collaboration and increased citations

- maximum visibility for your research: over $100 \mathrm{M}$ website views per year

At $\mathrm{BMC}$, research is always in progress.

Learn more biomedcentral.com/submissions 